\title{
Arctigenin induces apoptosis in human hepatoblastoma cells
}

\author{
Atsuki Naoe $^{1}$ (D) Tomonori Tsuchiya $^{1}$ - Yasuhiro Kondo ${ }^{1} \cdot$ Naoko Uga $^{1} \cdot$ Shunsuke Watanabe ${ }^{1} \cdot$ Toshihiro Yasui $^{1}$. \\ Fujio Hara ${ }^{1}$ Tatsuya Suzuki ${ }^{1}$
}

Accepted: 13 March 2019 / Published online: 19 March 2019

(c) The Author(s) 2019

\begin{abstract}
Purpose Arctigenin has been shown to have anti-tumor effects in various types of cancers. This study was conducted to verify these effects in the human-derived hepatoblastoma cell line, HUH-6 clone 5 (hereinafter, HUH-6).

Methods Arctigenin was added to cultured HUH-6 cells, and cellular activity was evaluated by MTS assay. To determine the relationship between reduced cellular activity and apoptosis, we measured the activities of caspase 3/7, 8 , and 9 and conducted flow cytometry with Annexin V/PI staining.

Results The MTS assay revealed that cellular activity decreased after arctigenin treatment in a concentration-dependent manner $\left(\mathrm{IC}_{50}=4 \mu \mathrm{M}\right)$. To investigate apoptosis induction, activity assays of caspase $3 / 7,8$, and 9 were performed. While caspase $3 / 7$ and 8 exhibited high activity, caspase 9 showed no activity. Thus, apoptosis induction may have involved the action of tumor necrosis factor receptor 1 (TNFR1). Flow cytometry conducted with Annexin V/PI staining revealed the occurrence of early apoptosis.

Conclusion We found that arctigenin has anti-tumor effects in HUH-6 cells in a concentration-dependent manner. Arctigenin may have exerted its anti-tumor effect by inducing apoptosis via TNFR1, which recruits Complex IIa to activate caspase 8 and 3/7. These results may be useful for developing therapeutic agents for hepatoblastoma.
\end{abstract}

Keywords Arctigenin $\cdot$ Hepatoblastoma $\cdot$ HUH-6 $\cdot$ Apoptosis $\cdot$ Cell death $\cdot$ Anti-tumor effect

\section{Introduction}

Hepatoblastoma is one of the major pediatric malignant solid tumors. In the last 20 years, hepatoblastoma has been reported in 0.6-1.2 individuals per million in the USA, accounting for $80 \%$ of the patients with pediatric malignant hepatic tumors [1]. The incidence of hepatoblastoma in Japan, at 8.5 persons per 100,000 individuals, is higher than that in Western countries [2]. Currently, the most effective treatment for clinical cases of hepatoblastoma is complete surgical resection. In some unresectable cases, liver transplants are performed. Furthermore, according to some reports, preoperative chemotherapy is expected to increase

Electronic supplementary material The online version of this article (https://doi.org/10.1007/s00383-019-04473-6) contains supplementary material, which is available to authorized users.

Atsuki Naoe

a-naoe@fujita-hu.ac.jp

1 Pediatric Surgery Department, Fujita Health University, Toyoake, Japan the probability of complete resection even in cases initially diagnosed as unresectable or distant metastases. Furthermore, post-operative chemotherapy has been reported to reduce the recurrence rate. Chemotherapy is crucial in treating hepatoblastoma [3]. Cisplatin is now used as an effective chemotherapeutic agent against hepatoblastoma. In addition, anthracyclines (doxorubicin or therarubicin) are the first choice for use [4]. However, in cases resistant to chemotherapy or when treatment causes negative side-effects, additional treatment options are necessary. Meanwhile, various Chinese herbal medicines have recently been reported to have anti-tumor effects. No Chinese herbal medicines have been reported as effective for treating hepatoblastoma, and thus studies are needed to identify such medicines.

We conducted the present study to investigate the antitumor effects of a new Chinese herbal medicine in human hepatoblastoma. Arctigenin, the main ingredient of Goboshi, i.e., burdock seeds, has been reported to exhibit antitumor effects against lung cancer, breast cancer, gallbladder cancer, hepatocellular carcinoma, colorectal cancer, etc. [5-10]. We examined the anti-tumor effects of arctigenin 
in the hepatoblastoma cell line HUH-6 clone 5 (hereinafter, referred to as $\mathrm{HUH}-6$ ). We previously reported that polyphyllin D exhibits anti-tumor effects in a human neuroblastoma cell line [11]. We tested the anti-tumor effects of arctigenin using the same methods as described in our previous study.

\section{Materials and methods}

\section{Arctigenin}

Systematic name: $(3 R, 4 R)-4-[(3,4-d i m e t h o x y p h e n y l) m e t h y l]$ dihydro-3-[(4-hydroxy-3-methoxyphenyl)methyl]-2(3H)furanone; molecular weight: 372.42 ; molecular structure: $\mathrm{C}_{21} \mathrm{H}_{24} \mathrm{O}_{6}$ (Fig. 1).

Arctigenin was obtained from Tocris Bioscience, Japan. It was dissolved in dimethyl sulfoxide to prepare a $1000 \mu \mathrm{M}$ solution.

\section{Human hepatoblastoma cell line}

HUH-6 was obtained from the JCRB Cell Bank. HuH-6 is hepatoblastomas cell line of the 12-month-old boy. For cell culture, Dulbecco's modified Eagle's medium (Thermo Fisher Scientific, Japan) supplemented with $10 \%$ fetal bovine serum, 100 units $/ \mathrm{mL}$ penicillin $\mathrm{G}$, and $100 \mu \mathrm{g} / \mathrm{mL}$ streptomycin was used. The culture conditions were as follows: $37{ }^{\circ} \mathrm{C}, 95 \%$ humidity, and $5 \% \mathrm{CO}_{2}$.

\section{MTS assay}

Before the administration of the drug, HUH-6 cells $\left(1 \times 10^{5}\right.$ cells $\left./ \mathrm{mL}\right)$ were seeded into 96 -well plates, and cultured for $24 \mathrm{~h}$ at $37{ }^{\circ} \mathrm{C}, 95 \%$ humidity, and $5 \% \mathrm{CO}_{2}$ conditions. The cells were then treated with either arctigenin or the vehicle for $48 \mathrm{~h}$. Then, $20 \mu \mathrm{L}$ of the reagent, 3-(4,5-dimethylthiazol-2-yl)-5-(3-carboxymethoxyphenyl)2-(4-sulfophenyl)-2 $H$-tetrazolium (MTS), was added to each

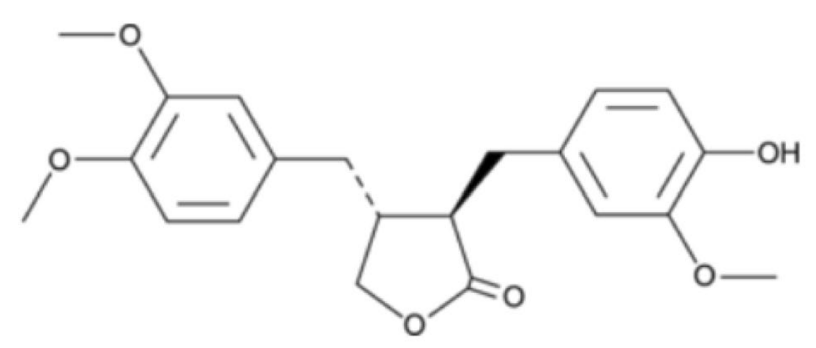

Fig. 1 Structural formula of arctigenin. IUPAC name: $(3 R, 4 R)-$ 4-[(3,4-dimethoxyphenyl)methyl]dihydro-3-[(4-hydroxy-3-methoxyphenyl)methyl]-2(3H)-furanone; molecular weight: $372.42 \mathrm{Da}$; and chemical formula: $\mathrm{C}_{21} \mathrm{H}_{24} \mathrm{O}_{6}$ well, and the cells were incubated for $2.5 \mathrm{~h}$ at $37^{\circ} \mathrm{C}, 95 \%$ humidity, and $5 \% \mathrm{CO}_{2}$ conditions. Cell viability was determined by measuring the absorbance at $490 \mathrm{~nm}$. A cell titer 96 aqueous one solution cell proliferation assay (Promega, Japan) was used as the MTS reagent. The cell viability was determined by absorbance relative to the vehicle (control), in reference to Bio-Rad's benchmark. Experiment was repeated thrice and verified.

\section{Caspase 3/7 activity assay}

Before the administration of the drug, HUH- 6 cells $\left(1 \times 10^{5}\right.$ cells $/ \mathrm{mL}$ ) were seeded into 96-well plates and cultured for $24 \mathrm{~h}$ at $37{ }^{\circ} \mathrm{C}, 95 \%$ humidity, and $5 \% \mathrm{CO}_{2}$ conditions. Next, the cells were treated with either arctigenin $(4 \mu \mathrm{M})$ or the vehicle for $24 \mathrm{~h}$. The Caspase-Glo ${ }^{\mathrm{TM}}$ 3/7 assay kit (Promega, Japan) was used for the measurement of enzyme activity; $100 \mu \mathrm{L}$ of the measuring reagent was added to the treated cells in each well and the cells were then cultured for $1 \mathrm{~h}$ at $37{ }^{\circ} \mathrm{C}, 95 \%$ humidity, and $5 \% \mathrm{CO}_{2}$ conditions. Perkin Elmer's ARVO was used to determine the level of luminescence. Experiment was repeated thrice and verified.

\section{Caspase 8 and 9 activity assays}

Before the administration of the drug, HUH-6 cells $\left(1 \times 10^{5}\right.$ cells $\left./ \mathrm{mL}\right)$ were seeded into 96 -well plates and cultured for $24 \mathrm{~h}$ at $37{ }^{\circ} \mathrm{C}, 95 \%$ humidity, and $5 \% \mathrm{CO}_{2}$ conditions. Next, the cells were treated with either arctigenin $(4 \mu \mathrm{M})$ or the vehicle for $4 \mathrm{~h}$. The Caspase-Glo ${ }^{\mathrm{TM}} 8 / 9$ Assay kit (Promega, Japan) was used for activity measurement; $100 \mu \mathrm{L}$ of the measuring reagent was added to the treated cells in each well, and the cells were then cultured for $0.5 \mathrm{~h}$ at $37{ }^{\circ} \mathrm{C}, 95 \%$ humidity, and $5 \% \mathrm{CO}_{2}$ conditions. Perkin Elmer's ARVO was used to determine the level of luminescence. Experiment was repeated thrice and verified.

\section{Annexin V and PI staining}

Annexin V-FITC Kit (MBL, Japan) was used for the detection of early apoptosis. HUH- 6 cells $\left(2 \times 10^{5}\right.$ cells $\left./ 2 \mathrm{~mL}\right)$ were seeded into 96-well plates and cultured for $24 \mathrm{~h}$ at $37{ }^{\circ} \mathrm{C}, 95 \%$ humidity, and $5 \% \mathrm{CO}_{2}$ conditions. Next, the cells were treated with either arctigenin $(4 \mu \mathrm{M})$ or vehicle for $2 \mathrm{~h}$. In order to prepare the cells for flow cytometry, they were washed with PBS and a binding buffer was added; the reaction between Annexin V-FITC and PI was induced at room temperature in the dark for 15 min. Flow cytometry (Beckman Coulter Gallios) was used to quantify the cells treated with Annexin V-FITC in FL1, FL2, and FL3. 


\section{Statistical analysis}

Student's $t$ test was used for analyzing the results of the caspase 3/7, 8, and 9 activity assays. A Dunnett test was conducted for MTS assay. The data are expressed as the mean \pm SD. JMP14 (SAS Institute Inc. USA) was used for statistical analysis. $P<0.05$ was considered statistically significant.

\section{Results}

We first examined the effect of arctigenin on the cell viability of human hepatoblastoma HUH-6. MTS assay results revealed that the cell viability decreased after arctigenin treatment in a concentration-dependent manner.

There were no significant decreases in cell viability in the $1 \mu \mathrm{M}$ arctigenin or control groups. Furthermore, a
Fig. 2 MTS assay using different concentrations of arctigenin. Arctigenin was found to demonstrate toxicity against HuH-6 cells in a concentration-dependent manner. The $\mathrm{IC}_{50}$ was found to be $4 \mu \mathrm{M}$. $* P<0.01$ compared with the untreated group

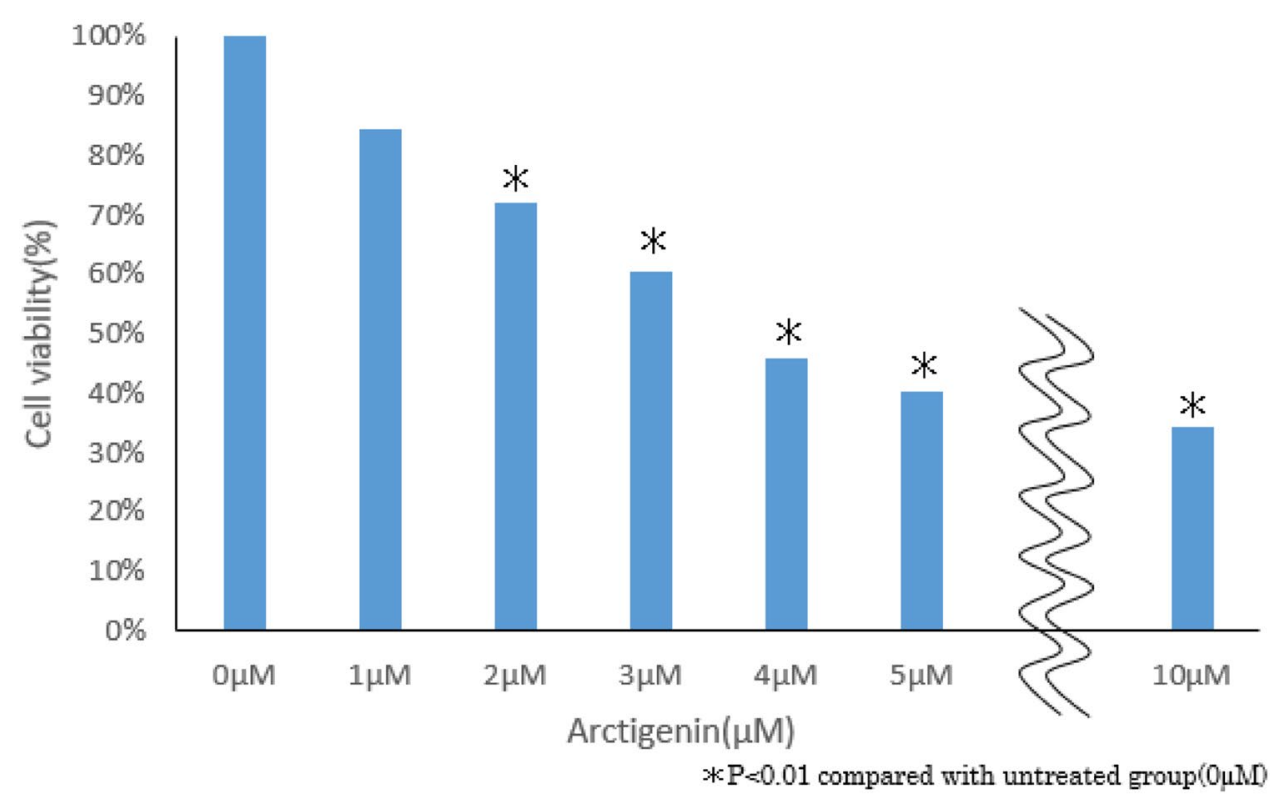

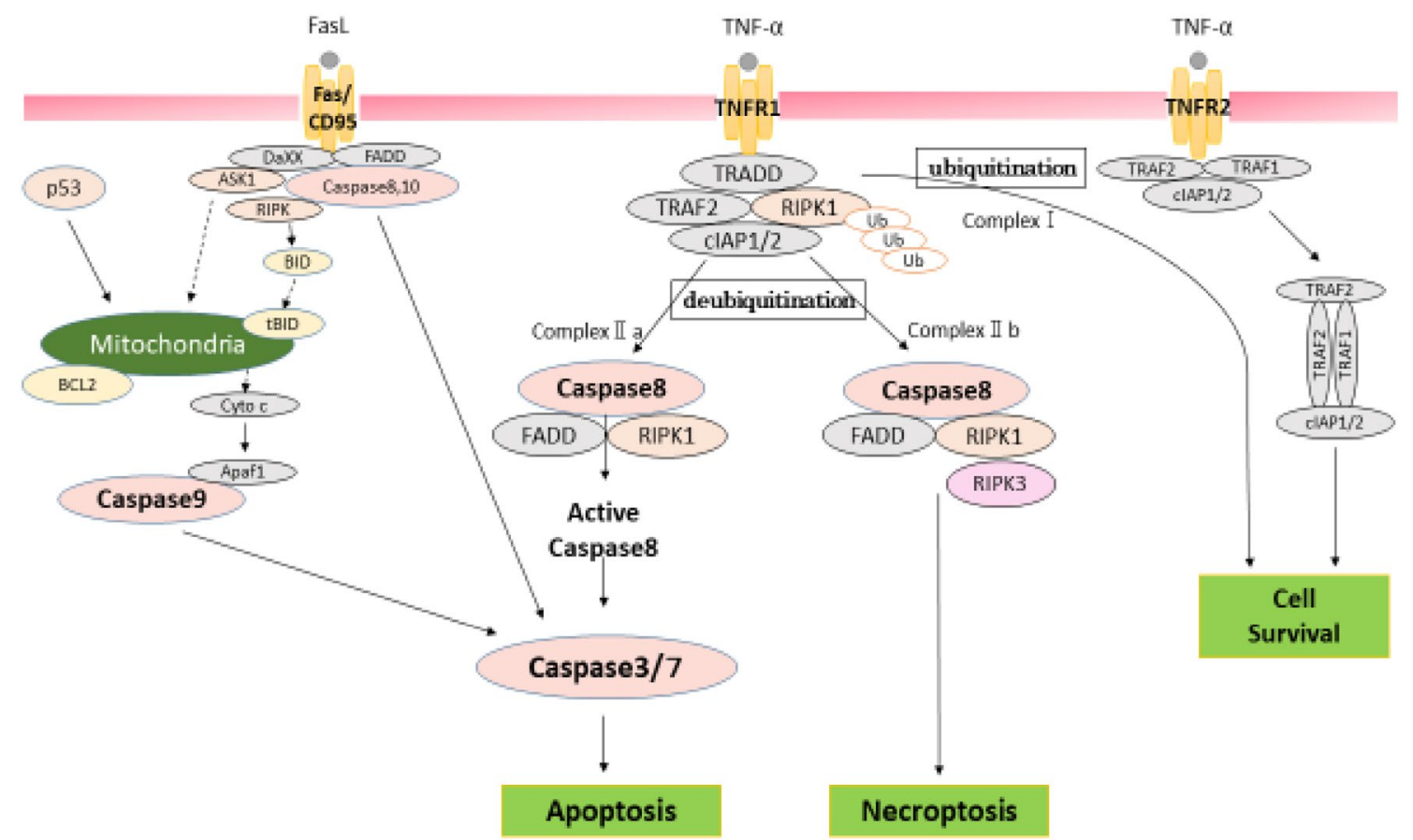

Fig. 3 Apoptosis, necroptosis, and survival—caspase cascade 
concentration-dependent decrease in cell viability was observed on treatment with $3 \mu \mathrm{M}(61 \%), 4 \mu \mathrm{M}(50 \%)$, and $5 \mu \mathrm{M}(40 \%)$ arctigenin. However, cell viability plateaued at $6 \mu \mathrm{M}$ and higher concentrations of arctigenin, with a $35 \%$ decrease in the $10 \mu \mathrm{M}$ group. The $\mathrm{IC}_{50}$ of arctigenin (wherein the growth of half of the cells was impaired) was $4 \mu \mathrm{M}$ (Fig. 2). If arctigenin treatment of HUH-6 cells causes cell apoptosis, regulation via caspases could be considered to be involved (Fig. 3).

Polyphyllin D induced apoptosis and necrosis in cells in a caspase-dependent manner as we reported previously [11]. Arctigenin also induced apoptosis in lung cancer, breast cancer, gallbladder cancer, hepatocellular carcinoma, and colorectal cancer cells [5-10]. We thus examined whether arctigenin similarly induces apoptosis in hepatoblastoma cells through caspase activation. After treating HUH-6 cells with $4 \mu \mathrm{M}$ arctigenin, we observed caspase $3 / 7$ activity by the Caspase-Glo ${ }^{\mathrm{TM}} 3 / 7$ activity assay (Fig. 4A), which indicated that apoptosis had occurred. Next, to elucidate the apoptosis pathway, we quantified the activation of apoptosis initiator caspases 8 and 9 in response to arctigenin using the Caspase-Glo ${ }^{\mathrm{TM}}$ 8/9 Assay kit. The activity of caspase 8 was found to be significantly high (Fig. 4B), while no caspase 9 activity was observed (Fig. 4C). Therefore, apoptosis via tumor necrosis factor receptor 1 (TNFR1) was speculated to have occurred.

We finally examined HUH-6 cells treated with arctigenin by annexin $\mathrm{V}$ and PI staining followed by flow cytometry. In the annexin $\mathrm{V}$ and PI staining analysis, a higher number of cells in the arctigenin-treated group were annexin V-FITCpositive relative to the vehicle-treated group, demonstrating the occurrence of early apoptosis (Fig. 5). Collectively, these findings suggested that arctigenin induces apoptosis of HUH-6 cells via TNFR1.

\section{Discussion}

To date, there have been no reports regarding the antitumor effects of the ingredients of Chinese herbal medicine on human hepatoblastoma. The present study was conducted with the aim of identifying a new herbal medicine with anti-tumor effects on the human hepatoblastoma cell line HUH-6. We then investigated arctigenin, a principal ingredient of burdock seeds, and its anti-tumor effects on HUH-6 cells. Burdock seeds are a component of Shofusan, which is used for treating eczema, chronic inflammation, and atopic constitution. It is a component of the herbal medicines, Saikoseikanto, which is often used to treat neurosis in children, chronic tonsillitis, eczema, chronic gastrointestinal disorders, and neurosis in weak constitution, and Kufugedokusan, which is effective against sore throat, tonsillitis, and peritonsillitis. In addition, the anti-tumor effect
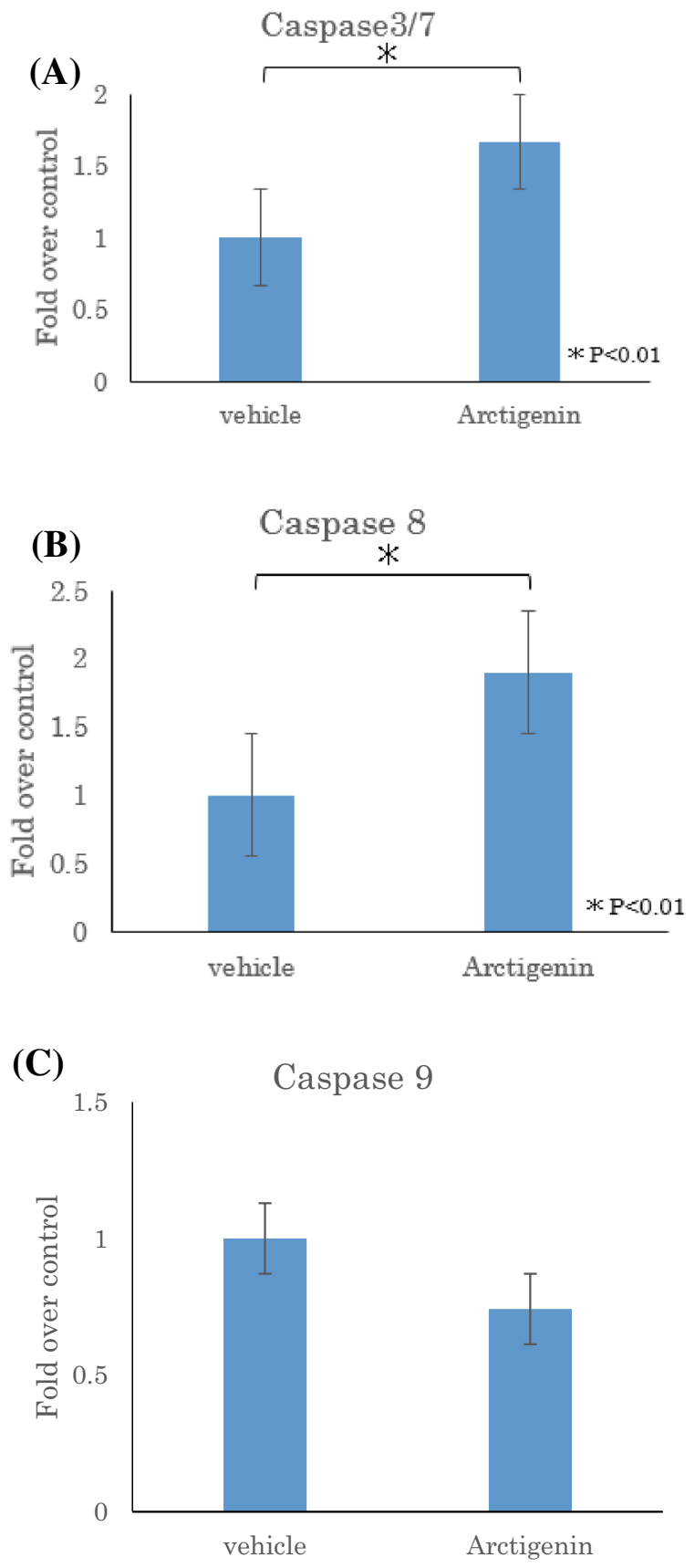

Fig. 4 Effect of arctigenin on caspase 3/7, 8, and 9 activities in cultured human hepatoblastoma cell lines. HuH-6 cells were treated with arctigenin $(4 \mu \mathrm{M})$, and the activities of caspase $3 / 7(\mathbf{A}), 8(\mathbf{B})$, and 9 (C) were measured. The vehicle group $(0 \mu \mathrm{M})$ served as the control. A $P<0.01$, B $P<0.01$, C $P=0.9$. Results are represented as the means \pm SD of three experiments

of arctigenin on cell lines derived from lung cancer, breast cancer, gallbladder cancer, colorectal cancer, and hepatocellular carcinoma cases has been reported, but not on those from hepatoblastomas [5-10]. In addition to its anti-tumor effects, arctigenin is thought to possess diverse properties, 


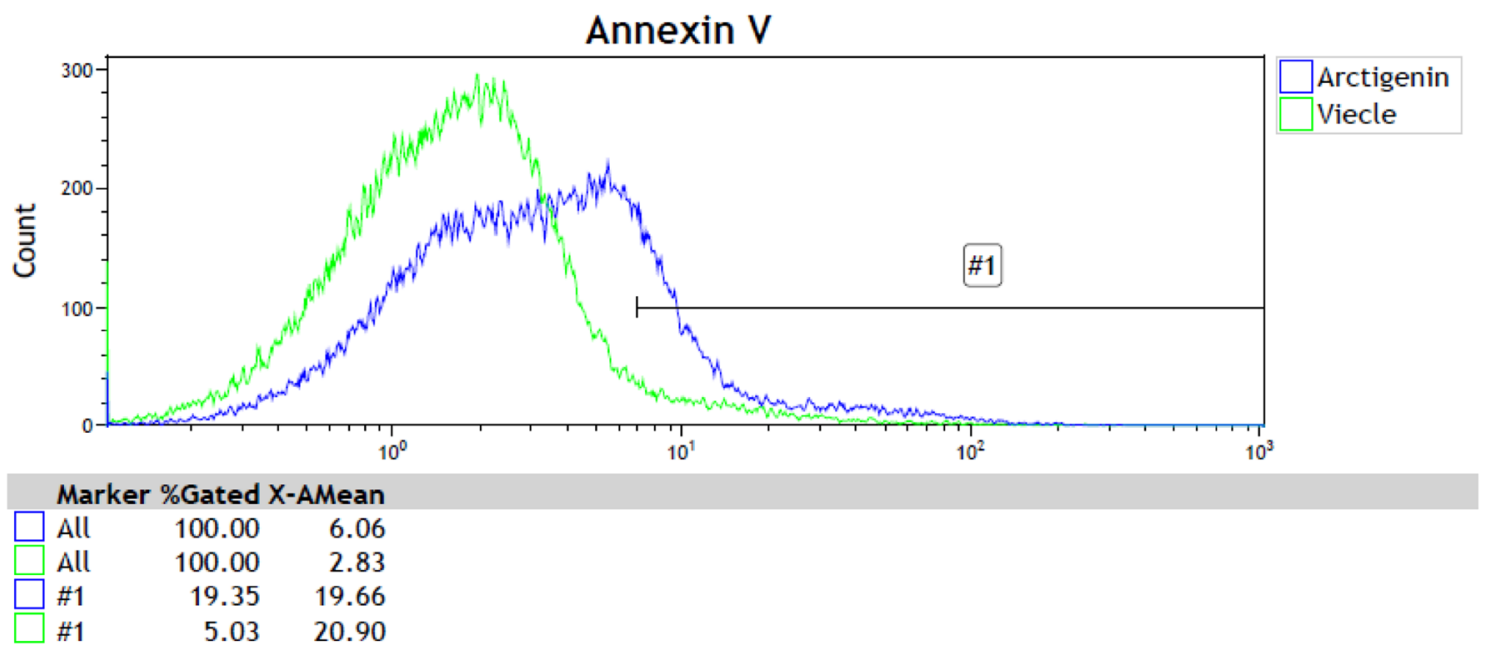

Fig. 5 Flow cytometry analysis with annexin V and PI staining. We measured the observation \#1 range after subtracting the values of the negative control. Compared with the control group, an increase in the

including anti-influenza, anti-inflammatory/analgesic, and anti-hypertension [12-14].

Arctigenin was added to cultured HUH-6 cells, and the MTS reagent was added after $48 \mathrm{~h}$ to determine cell viability. According to the results of the MTS assay, cell viability decreased after arctigenin treatment in a concentration-dependent manner. This is the first study to report that arctigenin has a potential anti-tumor effect on the human hepatoblastoma cell line, $\mathrm{HUH}-6$. The $\mathrm{IC}_{50}$ of arctigenin for HUH-6 cells was $4 \mu \mathrm{M}$.

Apoptosis and necroptosis are forms of programmed cell death. Previously, we treated cells from a neuroblastoma cell line with polyphyllin D and observed its antitumor effects. The results of our experiment indicated that necroptosis occurred in a cell line with the $M Y C N$ gene, while apoptosis occurred in a cell line lacking the $M Y C N$ gene [11]. Although the pathways mediating the antitumor effect of arctigenin are different in various tumors, apoptosis induction occurs in all tumors [5-10]. Exogenous apoptosis is initiated with the detection of an extracellular stress signal by a specific intramembrane/extramembrane receptor [15]. In contrast, endogenous apoptosis is initiated by a perturbation in the mitochondria caused by a cellular stress signal [16]. Activation and induction of endogenous apoptosis is mediated through the binding of ligands to a death receptor such as TNFR1, tumor necrosis factor-related apoptosis-inducing ligand (TRAIL) receptor, and Fas 9/10 [17, 18]. After ligand binding, the cells may either survive or undergo apoptosis or necroptosis, depending on the complex formed. Through ligand (TNF) binding, TNF-receptor-associated death domain (TRADD) recruits Complex I (cell survival complex), which consists of RIPK1 and ubiquitin E3 ligase. In Complex I, RIPK1 number of Annexin-positive cells was observed following arctigenin administration from 5.03 to $19.35 \%$, indicating that early apoptosis had occurred

is polyubiquitylated and degraded, without inducing cell death. When RIPK1 is deubiquitinated, it dissociates from TRADD and forms either Complex IIa or Complex IIb [19, 20]. After the formation of Complex IIa, the cells undergo apoptosis through activation of caspase 8 , whereas the formation of Complex IIb, sometimes called the "necrosome", inhibits activation of caspase 8 to induce the necroptosis pathway (Fig. 3) [19, 20].

To determine which caspase cascade mediates the antitumor effect of arctigenin on HUH-6 cells, we assayed the activity of caspase $3 / 7,8$, and 9 . In this study, we detected the activation of effector caspase $3 / 7$ and the initiator caspase for TNFR1, caspase 8, while no activity was observed for caspase 9, the initiator caspase for Fas ligand. Therefore, we speculated that apoptosis is induced through the activation of caspase 8 and 3/7, by the recruitment of Complex IIa via TNFR1.

We examined whether early apoptosis occurs via TNFR1 involving caspase 8 as shown in Fig. 3. Annexin $\mathrm{V}$ binds only to cells undergoing apoptosis. An increase in the number of Annexin-positive cells was observed following arctigenin administration from 5.03 to $19.35 \%$, indicating that early apoptosis had occurred. We conducted Annexin V and PI staining and detected early apoptosis. Thus, for the first time, we found that arctigenin exerts anti-tumor effects by inducing the apoptosis of HUH-6 cells via TNFR1.

Fifteen types of hepatoblastoma cell lines are sold throughout the world [21]. However, only the HUH-6 hepatoblastoma cell line is available in Japan. Further studies are needed to evaluate the effects of arctigenin in other cell lines and in vivo. Chinese medicine, including arctigenin, shows potential for treating human hepatoblastoma. 
Acknowledgements We gratefully acknowledge the work of past and present members of our laboratory.

Funding Not applicable.

\section{Compliance with ethical standards}

Conflict of interest This study was not funded. All listed authors (Atsuki Naoe, Tomonori Tsuchiya, Yasuhiro Kondo, Naoko Uga, Shunsuke Watanabe, Toshihiro Yasui, Fujio Hara, Tatsuya Suzuki) declare that he/she has no conflict of interest and has not received research grants for this study.

Research involving human participants and/or animals All procedures performed in studies involving human participants were in accordance with the ethical standards of the institutional and/or national research committee and with 1964 Helsinki declaration and its later amendments or comparable ethical standards.

Informed consent For this study, formal consent is not required.

Open Access This article is distributed under the terms of the Creative Commons Attribution 4.0 International License (http://creativeco mmons.org/licenses/by/4.0/), which permits unrestricted use, distribution, and reproduction in any medium, provided you give appropriate credit to the original author(s) and the source, provide a link to the Creative Commons license, and indicate if changes were made.

\section{References}

1. Coran AG, Caldamone A, Adzick NS et al (2012) Pediatric surgery E-book, 7th edn. Elsevier Health Sciences, Netherlands, pp 466-476

2. Katanoda K, Shibata A, Matsuda T et al. Childhood, adolescent and young adult cancer incidence in Japan in 2009-2011 (2017) Jpn J Clin Oncol 47:762-771

3. Meyers RL, Maibach R, Hiyama E et al (2017) Risk-stratified staging in paediatric hepatoblastoma: a unified analysis from the Children's Hepatic tumors International Collaboration. Lancet Oncol 18:122-131

4. Yang T, Tan T, Yang J et al (2018) Ruptured hepatoblastoma successfully treated with cisplatin monochemotherapy: a case report. Mol Clin Oncol 9:223-225

5. Han YH, Kee JY, Kim DS et al (2016) Arctigenin inhibits lung metastasis of colorectal cancer by regulating cell viability and metastatic phenotypes. Molecules 21(9):E1135. https://doi. org/10.3390/molecules21091135

6. Xu Y, Lou Z, Lee SH (2017) Arctigenin represses TGF-b-induced epithelial mesenchymal transition in human lung cancer cells. Biochem Biophys Res Commun 493:934-939
7. Feng T, Cao W, Shen W et al (2017) Arctigenin inhibits STAT3 and exhibits anticancer potential in human triple-negative breast cancer therapy. Oncotarget 8(1):329-344

8. Zhang M, Cai S, Zuo B et al (2017) Arctigenin induced gallbladder cancer senescence through modulating epidermal growth factor receptor pathway. Tumor Biol. https://doi.org/10.1177/10104 28317698359

9. Sun Y, Tan YJ, Lu ZZ et al (2018) Arctigenin inhibits liver cancer tumorigenesis by inhibiting gankyrin expression via C/EBPa and PPARa. Front Pharmacol 9:268. https://doi.org/10.3389/fphar .2018 .00268

10. Li QC, Liang Y, Tian Y et al (2016) Arctigenin induces apoptosis in colon cancer cells through ROS/p38MAPK pathway. J Buon 21(1):87-94

11. Watanabe S, Suzuki T, Hara F et al (2017) Polyphyllin D, a steroidal saponin in Paris polyphylla, induces apoptosis and necroptosis cell death of neuroblastoma cells. Pediatr Surg Int 33(6):713-719

12. Hayashi K, Narutaki K, Nagaoka Y (2010) Therapeutic effect of arctiin and arctigenin in immunocompetent and immunocompromised mice infected with influenza A virus. Biol Pharm Bull 33:1199-1205

13. Zhao F, Wang L, Liu K (2009) In vitro anti-inflammatory effects of arctigenin, a lignan from Arctium lappa L., through inhibition on iNOS pathway. J Ethnopharmacol 122(3):457-462

14. Ichikawa K, Kinoshita $\mathrm{T}$, Nishibe $\mathrm{S}$ et al (1986) $\mathrm{The}^{\mathrm{Ca}^{2+}}$ antagonist activity of lignans. Chem Pharm Bull 34:3514-3517

15. Galluzzi L, Vitale I, Abrams JM et al (2012) Molecular definitions of cell death subroutines: recommendations of the Nomenclature Committee on Cell Death 2012. Cell Death Differ 19:107-120

16. Inoue S, Browne G, Melino G et al (2009) Ordering of caspases in cells undergoing apoptosis by the intrinsic pathway. Cell Death Differ 16(7): 1053-1061

17. Degterev A, Huang Z, Boyce M et al (2005) Chemical inhibitor of nonapoptotic cell death with therapeutic potential for ischemic brain injury. Nat Chem Biol 1:112-119

18. Holler N, Zaru R, Micheau O et al (2000) Fas triggers an alternative, caspase-8-independent cell death pathway using the kinase RIP as effector molecule. Nat Immunol 1:489-495

19. Moriwaki K, Chan FK (2013) RIP3: a molecular switch for necrosis and inflammation. Genes Dev 27:1640-1649

20. Feoktistova M, Wallberg F, Tenev T et al (2016) Techniques to distinguish apoptosis from necroptosis. Cold Spring Harb Protoc. https://doi.org/10.1101/pdb.top070375

21. Rishi RR, Kimberlee KS, Ruth I. H et al(2016) Hepatoblastoma: a need for cell lines and tissue banks to develop targeted drug therapies. Front Pediatr. https://doi.org/10.3389/fped.2016.00022

Publisher's Note Springer Nature remains neutral with regard to jurisdictional claims in published maps and institutional affiliations. 